\section{A Novel 3-Dimensional Echocardiographic Transillumination Rendering With Transparency in the Evaluation of Paravalvular Leak After Transcatheter Aortic Valve Implantation}

Masaki Izumo, MD, PhD; Kazuaki Okuyama, MD; Yoshihiro J Akashi, MD, PhD

$\mathbf{P}$ aravalvular leak (PVL) after transcatheter aortic valve implantation (TAVI) has been associated with poor prognoses, and its diagnosis is important when deciding strategies that consider post-dilatations to minimize the PVL. ${ }^{1}$ Recently, 3-dimensional (3D) echocardiography transillumination with transparency (TrueVue Glass; Philips, Andover, MA, USA) allows new photorealistic imaging of cardiac structures, which may be viewed through tissue. ${ }^{2}$

An 83-year-old male with aortic stenosis underwent TAVI. Mild-to-moderate PVL was observed after the valve implantation (Figure A-C). In a TrueVue Glass (Figure C, Supplementary Movie 1), the location, width, and jet direction through the left ventricle of the PVL were clearly depicted; PVL decreased after post-dilatation (Figure D-F, Supplementary Movie 2).

3D color Doppler echocardiography is useful for evaluating PVL because it can be used without anatomical restriction. However, the image analysis is time-consuming and it is not widely used for intraprocedural echocardiography. By using a TrueVue Glass, it is possible to clearly demonstrate the regurgitant origin and trajectory in realtime. Although the vena contracta width can be easily obtained from this image, there have been no published cut-off values for determining the severity of a PVL, and further studies are needed.

\section{Disclosures}

Y.J. Akashi is a member of Circulation Journal's Editorial Team.

\section{References}

1. Hayashida K, Lefèvre T, Chevalier B, Hovasse T, Romano M, Garot $\mathrm{P}$, et al. Impact of post-procedural aortic regurgitation on mortality after transcatheter aortic valve implantation. JACC Cardiovasc Interv 2012; 5: 1247-1256.

2. Karagodin I, Addetia K, Singh A, Dow A, Rivera L, DeCara $\mathrm{JM}$, et al. Improved delineation of cardiac pathology using a novel three-dimensional echocardiographic tissue transparency tool. J Am Soc Echocardiogr 2020; 33: 1316-1323.

\section{Supplementary Files}

Supplementary Movie 1. TrueVue Glass before post-dilatation. Supplementary Movie 2. TrueVue Glass after post-dilatation.

Please find supplementary file(s);

http://dx.doi.org/10.1253/circj.CJ-20-1183

Received November 17, 2020; revised manuscript received December 8, 2020; accepted December 10, 2020; J-STAGE Advance Publication released online January 29, 2021 Time for primary review: 18 days

Division of Cardiology, Department of Internal Medicine, St. Marianna University School of Medicine, Kawasaki, Japan

Mailing address: Masaki Izumo, MD, PhD, Division of Cardiology, Department of Internal Medicine, St. Marianna University School of Medicine, 2-16-1 Sugao, Miyamae-ku, Kawasaki 216-8511, Japan. E-mail: heartizumo@yahoo.co.jp

All rights are reserved to the Japanese Circulation Society.

For permissions, please e-mail: cj@j-circ.or.jp

ISSN-1346-9843

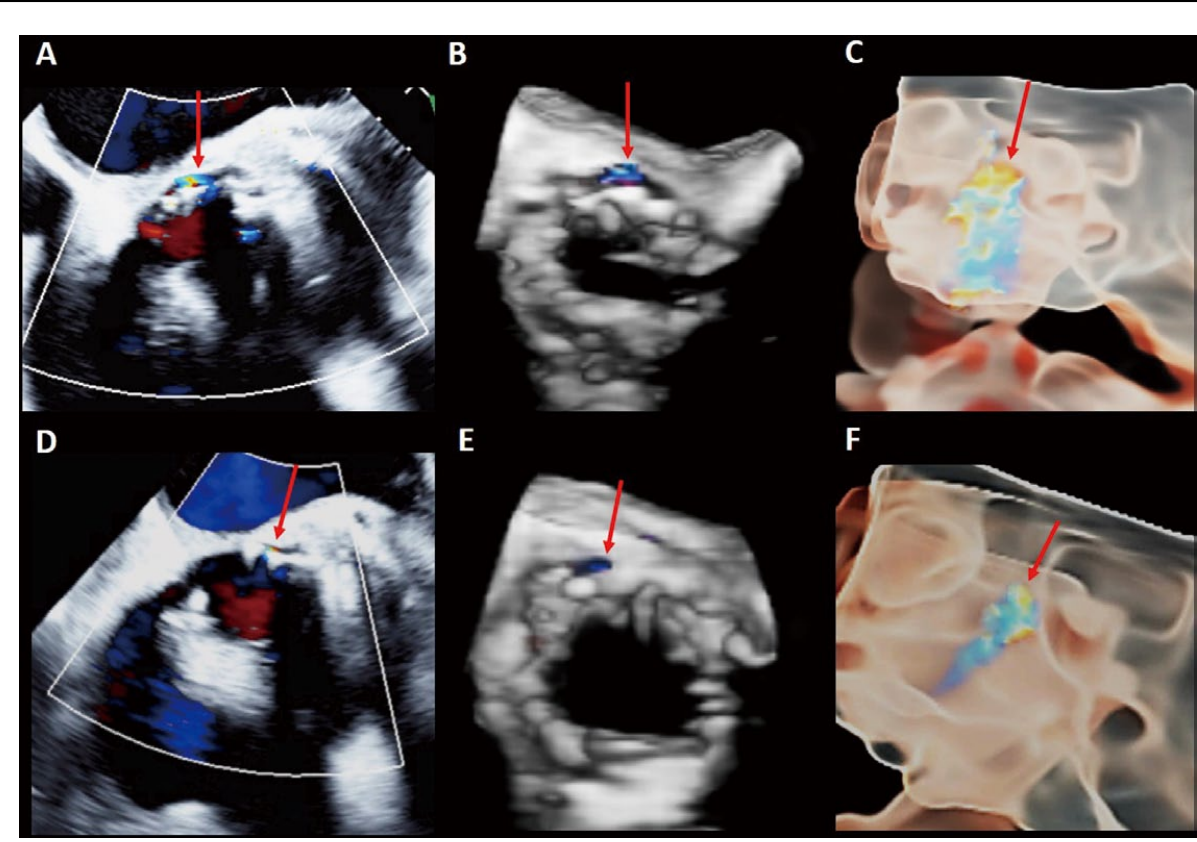

Figure. 2D and 3D color Doppler echocardiography showed mild-to-moderate paravalvular leak (PVL) at 11 to 1 o'clock (A and $\mathbf{B}$, red arrows), which was reduced by postdilatation (D and $\mathbf{E}$, red arrows), but the jet origin and direction were not identified. A TrueVue Glass showed jet origin and direction before (C, red arrow) and after post-dilatation (F, red arrow). 